\section{A convenient method for inserting small feeding tubes}

JOHN D. BULLOCK From the Harvard Medical School, Boston, Massachusetts, U.S.A.

Those involved in the care of postoperative and chronically ill patients are familiar with the use of Levine tubes for feeding purposes. Levine tubes, however, which remain in the stomach for extended periods can cause oesophagitis leading to oesophageal stricture (Waldman and Berun, 1965). For this reason, small plastic tubes are used for prolonged feeding.

These small tubes, however, suffer the disadvantage that they are frequently difficult to pass into the stomach. The manufacturer recommends placing the tube in ice water in order to stiffen the plastic and thus make it easier to insert but, in the process of insertion, the tube becomes warmer and requires refreezing if the first attempt is not immediately successful.

Another method is to place the smaller feeding tube alongside a Levine tube and to place an empty half capsule over, or a catgut stitch around, the ends of the two tubes, and to pass the tubes as a unit. This method is advantageous because it is easier to insert the tube combination than the smaller tube by itself. However, this method too has its shortcomings. If a capsule is used, the tubes must remain in the stomach until the capsule dissolves, and then the Levine tube is withdrawn. The capsule can prematurely dissolve or can become dis- lodged thus separating the two tubes. There is also the danger that the tube combination will be passed into the trachea instead of the oesophagus, and the patient may aspirate the capsule. If a catgut stitch is used, a waiting period of several days is required before the Levine tube can be withdrawn. In either case, insertion can be complicated by the smaller tube becoming wrapped around the outside of the Levine tube making insertion of the combination and withdrawal of the Levine tube difficult.

An additional "way to insert such a tube is to tie a small portion of a finger cot to the end of the tube with a suture and inject this finger cot with a small amount of mercury. The small bag of mercury will usually be swallowed without difficulty and can remain in place for a long time without producing any irritation' (Zuidema and Weldon, 1965). There exists the possibility that the cot will break, or become dislodged, thus exposing the patient to the toxic mercury.

If these methods fail, the patient may undergo a gastrostomy feeding tube procedure, with all its hazards. When a gastrostomy feeding tube is not possible and nasogastric intubation cannot be executed, parenteral administration of fat emulsions and protein hydrolysates is attempted with the hazards of colloid reactions, sclerosis of veins, etc.

With this in mind, the following method was developed.

\section{METHOD}

The lower (smaller) end of a rubber Levine tube (Davol no. 18 , or Rüsch no. 18) is cut off in order to give an overall length of 20 inches. This end is then tapered slightly. Holes, $8 \mathrm{~mm}$ by $3 \mathrm{~mm}$, (with the long axis of the hole

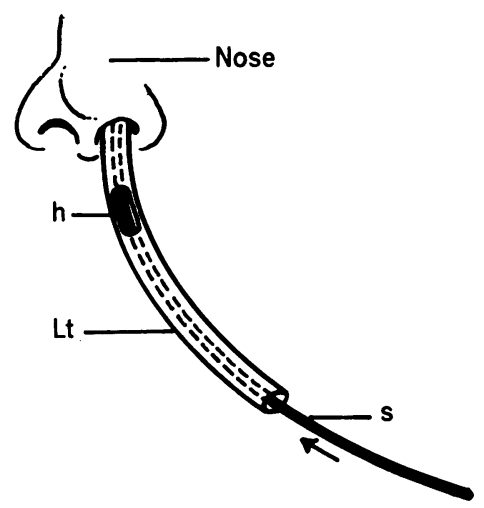

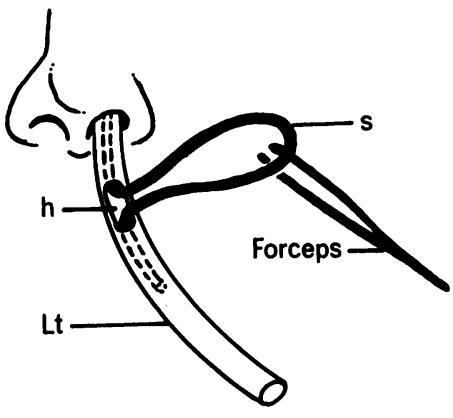

FIG. 2

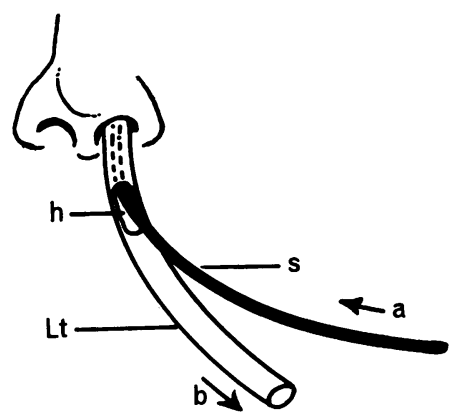

FIG. 3

FIG. 1

FIG. 1. The Levine tube with the small feeding tube extending from it. The arrow indicates that the small tube is to be pushed down into the Levine tube. Lt =Levine tube; $s=$ small feeding tube; $h=h o l e$ no. 1 .

FIG. 2. The small feeding tube being pulled out with forceps through hole no. 1 in the side of the Levine tube.

FIG. 3. Arrow a indicates that the small tube is to be pushed through hole no. 1 down into the Levine tube and then the Levine tube is to be withdrawn from the nose (as indicated by arrow b) until hole no. 2 is reached. 
along the length of the tube) are placed 5, 10, and 15 in. from the upper (larger) end, using ordinary scissors. The upper end of a small plastic feeding tube (Mead-Johnson, list no. 290 or Argyle, size $8 \mathrm{Fr}$ length 42 in., cat no. AR-30R) is cut off just below the plastic adaptor. The small tube is then slid down the centre of the Levine tube until the lower ends of the two tubes meet. The outer surface of the Levine tube is then lubricated, and the Levine tube is passed through the nose and down the oesophagus, in the usual manner, until only about 5 inches of the Levine tube protrude from the nose. With the Levine tube thus in place, the small tube extends out of the end of the Levine tube. The smaller tube is then pushed down into the Levine tube, as in Figure 1. Then the exposed ends of the two tubes are flush against one another. Using a pair of ordinary small forceps, the small tube is grasped through the hole in the Levine tube, and pulled out of the side, as in Figure 2. Figure 3 shows that the small tube now extends out of the hole in the side of the Levine tube. The arrow $a$ indicates that the small tube is to be pushed back through the hole and down the Levine tube until the end of the small tube reaches hole no. 1. Arrow $b$ indicates that the Levine tube is to be pulled out of the nose until the next hole is reached (hole no. 2). The small tube is then grasped with forceps through hole no. 2 and pulled out, as before. It is once again pushed back through hole no. 2, and the Levine tube is again withdrawn from the nose until hole no. 3 is reached. This process is repeated until, when the small tube is pushed back through hole no. 3, the Levine tube is pulled out of the nose and the smaller tube remains in place in the stomach.

A no. 15 gauge angiocath (Bardic, catalogue no. 1961 or Argyle no. AR 3216) is then inserted into the end of the small tube, and the needle portion is withdrawn, leaving the plastic tube and adaptor in place. To the adaptor is attached intravenous tubing for bottle feeding or a syringe for syringe feeding.

\section{RESULTS}

With practice it is possible to insert the small plastic feeding tube in two to three minutes. This method has been successful in six patients in whom all other techniques of nasogastric intubation had proved impossible.

\section{CONCLUSION}

Once a Levine tube has been cut as described above, it may be used again and again.

This method is more favourable than the others described for the following reasons: (1) it is easier to insert a Levine tube than the smaller tube; (2) it is easier to insert a Levine tube than the two-tube combination; (3) there is no mandatory waiting period before removing the Levine tube; (4) freezing the small tube is unnecessary; (5) there is no danger of aspiration of a capsule; (6) the danger of regurgitrant oesophagitis is minimized because the tube is smaller in size than a Levine tube; (7) it may prevent a feeding gastrostomy procedure; (8) it may prevent colloid reactions and sclerosis of veins; and (9) it may prevent mercury poisoning.

Dr William Silen helped in the preparation of this work.

\section{REFERENCES}

Waldman, I., and Berun, L. (1965). Stricture of the esophagus due to nasogastric intubation. Amer. J. Roentgenol., 94, 321-324.

Zuidema, G. D., and Weldon, C. S. (1965). Management of the surgical patient. In Surgery, $A$ Concise Guide to Clinical Practice, 2nd ed., edited by G. L. Nardi and G. D. Zuidema, p. 39. Boston: Little, Brown and Co. 